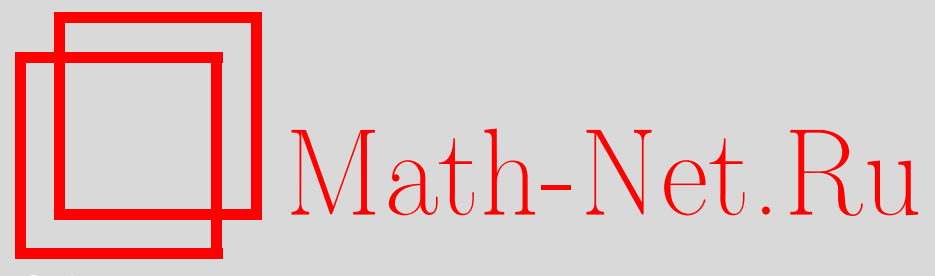

А. Варламов, С. Шарапов, Ю. Шикина, Термоэлектричество: от дуги Алессандро Вольта до феррожидкостных термоэлектрических генераторов, Квант, 2021, номер 7, 8-18

DOI: https://doi.org/10.4213/kvant20210702

Использование Общероссийского математического портала Math-Net.Ru подразумевает, что вы прочитали и согласны с пользовательским соглашением http://www.mathnet.ru/rus/agreement

Параметры загрузки:

IP : 52.205 .19 .152

26 апреля 2023 г., 12:03:48

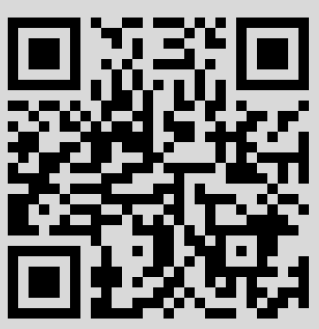




\section{Термоэлектричество: от дуги Алессандро Вольта до феррожидкостных термоэлектрических генераторов}

\section{А.ВАРЛАМОВ, С.ШАРАПОВ, Ю.ШИКИНА}

Современного человека трудно удивить вопросами, что такое электричество или как происходит передача тепла - каждый имеет по этим поводам свое мнение. Кто теоретическое, основанное на изучении физики, а большинство - памятуя незабываемые ощущения от удара током в процессе починки розетки при неотключенном напряжении на щитке или от случайного прикосновения к раскаленному утюгу. Но, конечно, гораздо меньшее число читателей знакомо с явлением термоэлектричества. В древнегреческой мифологии важное место занимают кентавры - дикие, смертные существа с головой и торсом человека на теле лошади, обитатели гор и лесных чащ. Явление термоэлектричества подобно кентавру - здесь электрическое напряжение между краями образца возникает в результате его неравномерного нагрева.

\section{Диспут между Луиджи Гальвани и Алессандро Вольта}

История открытия и последующего изучения термоэлектричества насчитывает более двух веков и начинается с дискуссии между Луиджи Гальвани и Алессандро Вольта.

В середине XVIII века популярной темой в науке стало изучения электрических явлений, в том числе и животного электричества, например порождаемого электрическими скатами. Ввиду этого, профессор Болонского университета физиолог Луиджи Гальвани стал изучать, что происходит с препарированной лягушкой при пропускании через нее тока. В результате много-

DOI: https://doi.org/10.4213/kvant20210702 численных экспериментов Гальвани убедился, что каждый раз, когда он, прикасаясь к нервам лягушки присоединенным к электрической машине проводником, извлекал из нее искру, лягушку охватывала судорожная дрожь. Далее Гальвани продолжил свои опыты и обнаружил такие же сокращения при соединении мышц и нервов только что препарированной лягушки металлической дугой (рис.1). При этом особое внимание Гальвани привлекло то обстоятельство, что сокращение мышц лягушки оказывается значительно более сильным, если металлическая дуга составлена последовательно из двух различных металлов: например, железа и меди (или, что гораздо лучше, серебра). Эти эксперименты привели знаменитого итальянца к заключению, что электричество свойственно самому животному: от нервов к мышцам как бы протекает флюид и образуется цепь (как при разряде лейденской банки).

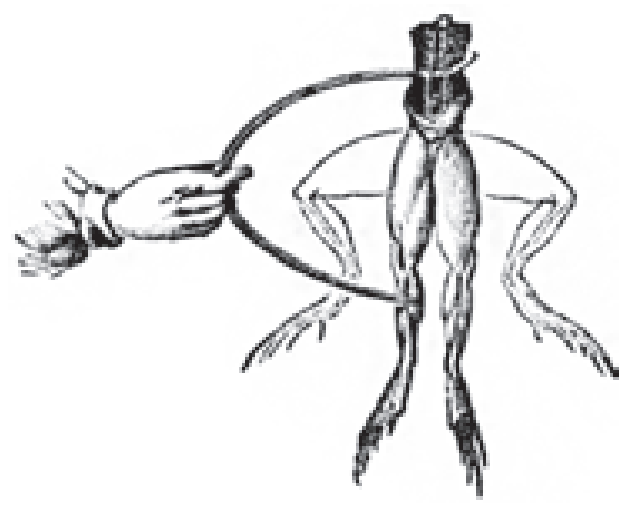

Рис. 1. Луиджи Гальвани обнаружил сокращения мышц препарированной лягушки при их соединении металлической дугой 


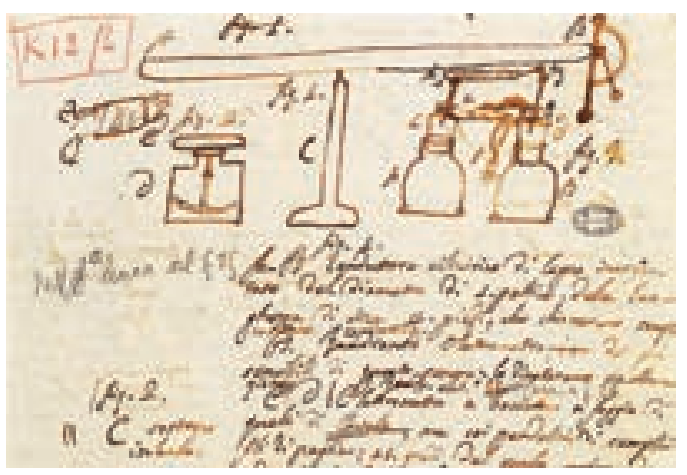

Рис. 2. Эскизы инструментов, которыми пользовался Алессандро Вольта в экспериментах с лягушками. Мемуар о животном электричестве, 14 мая 1792 года (Архив А.Вольты, лист К13, Ломбардская академия наук и литературы)

Профессор Павийского университета физик и химик Алессандро Вольта относился с недоверием к так называемому животному электричеству. И тем не менее, по настоянию коллег, он повторяет описанные в работе Гальвани опыты (рис.2). В результате его скептицизм стал рассеиваться, и 3 апреля 1792 года он пишет Гальвани: «Итак, вот я наконец обращен. С тех пор как я стал сам очевидцем и наблюдал эти чудеса, я, пожалуй, перешел от недоверия к фанатизму». В публичной лекции 5 мая 1792 года Вольта рассказывает об опытах Гальвани, превозносит их, но вместе с тем высказывает мысль, что лягушка может представлять собою лишь измерительный прибор, электрометр, в десятки раз более чувствительный, чем уже давно существующий электрометр с золотыми листочками. Вольта настойчиво привлекает внимание к одной физической особенности опытов Гальвани: для того чтобы вызвать сокращение мышц, образующие дугу металлы должны быть различными. Он спрашивает: действительно ли металлические проводники служат лишь для того, чтобы, соприкасаясь друг другом, установить связь, предоставляющую электрическому флюиду путь, по которому тот естественно стремится перейти из одного места в другое? Действительно ли их роль чисто пассивна или же они являются активными агентами, приводящими в движение электрический заряд? В даль-
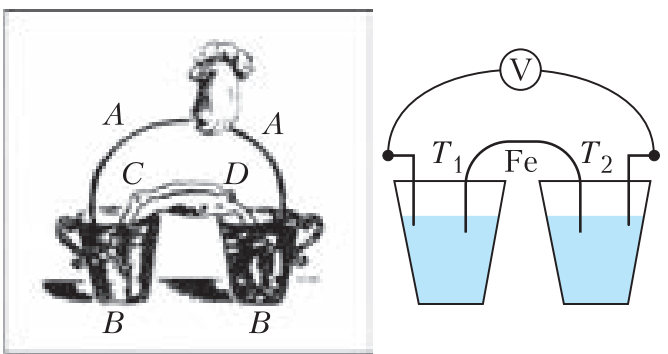

Рис. 3. Алессандро Вольта использует в качестве дуги проводник из одного металла, но помещает концы мышцы лягушки и концы проводника в сосуды с холодной и горячей водой. На правом рисунке вместо мышцы лягушки изображен вольтметр

нейших своих опытах Вольта показывает, что мышца, по существу, не участвует в создании самого явления, ее сокращение есть эффект протекания заряда, генерируемого контактом двух различных металлов. Таким образом, фактически он открывает явление, которое связано с контактной разностью потенциалов.

В своих сомнениях Вольта идет далее. В качестве дуги он пробует использовать проводник из одного металла, но помещает концы мышцы лягушки и концы дуги в сосуды с холодной и горячей водой (рис.3). Мышца сокращается и в этом эксперименте, что позволяет ученому объяснить протекание электрического флюида (заряда) неравномерным нагревом металлического проводника. Связь между электрическим током и разностью температур обнаружена!

В процессе экспериментов с металлической дугой Вольта осознал, что прохождение тока по мышце лягушки есть не что иное как его протекание в кислотной среде. В результате он создал свою знаменитую батарею, так называемый вольтов столб - последовательность чередующихся пластин из двух металлов (например, свинца и меди), разделенных пропитанной кислотой (уксусом) тканью. На этом же принципе работают батареи и сегодня.

\section{Йенская школа и открытие Иоганна Зеебека}

Томас Иоганн Зеебек, немецко-эстонский физик, химик и врач, родился в 1770 году в ганзейском городке Ревель (ныне 
Таллин). В возрасте 17 лет он едет в Германию, чтобы изучать медицину, и в 1792 году сдает на отлично выпускные экзамены по медицине. Однако под сильным влиянием харизматичного профессора физики Георга Кристофа Лихтенберга Зеебек решает посвятить себя физике. В марте 1802 года Зеебек получает докторскую степень и переезжает в Йену. Здесь он попадает в бурлящую интеллектуальную среду, центральной фигурой которой является Иоганн Вольфганг Гёте, великий поэт, страстный естествоиспытатель и исследователь. Будучи влиятельным администратором Веймарского двора, он помогает молодым талантам начать их академические карьеры.

Зеебек впервые встретился с Гёте на обеде в декабре 1803 года, где знакомится и со своим сверстником, будущим прославленным философом Гегелем, с которым они становятся друзьями. Гёте ищет ассистента, для помощи в его оптических исследованиях, и Зеебек становится для него прекрасным выбором. Их продолжительное сотрудничество привело к тому, что внесенный Зеебеком вклад стал важной частью «Теории цветов» - главного научного произведения Гёте. Тем не менее, близость к фигуре Гёте подавляет Зеебека, и он покидает Йену. В 1818 году, после ряда скитаний по университетским городам Германии, Зеебек за его работы по оптике избирается членом-корреспондентом Берлинской академии наук.

21 июля 1820 года датский ученый, физик Ханс Кристиан Эрстед публикует свое знаменитое эссе «Эксперименты о влиянии электрического тока на магнитную иглу», которое открывает дверь в новую область науки - электромагнетизм. Зеебек оставляет в стороне свои оптические эксперименты и углубляется в идеи Эрстеда. Очень скоро, после нескольких месяцев работы, Зеебек приходит к главному результату своей научной карьеры - открытию явления, названного им «термомагнетизмом», по аналогии с «электромагнетизмом» Эрстеда. Об этом он сообщает на заседании Берлинской академии
16 августа 1821 года. Впоследствии Эрстед посещает лабораторию Зеебека в Берлине с целью ознакомиться с его экспериментами и уже в марте 1823 года сообщает об открытии Зеебека на заседании Французской академии наук. При этом он дает физически правильную интерпретацию нового явления и вводит для него принятый сегодня термин «термоэлектричество» . Эрстед высоко оценивает работу Зеебека, называя ее «самым прекрасным из открытий, выросших из его исследований».

Количественной характеристикой термоэлектрического эффекта служит коэффициент Зеебека. Он характеризует разность потенциалов между концами проводника $\Delta U$, возникающую при поддержании между ними разности температур $\Delta T$ :

$$
S=-\frac{\Delta U}{\Delta T}=\frac{E}{\Delta T / \Delta x},
$$

где $E=-\frac{\Delta U}{\Delta x}-$ напряженность возникающего в проводнике электрического поля, а $\frac{\Delta T}{\Delta x}$ - градиент температуры. Соответственно, напряжение, вырабатываемое термопарой из двух различных металлов $A$ и $B$ с разностью температур $T_{1}$ и $T_{2}$ между их концами, равно

$$
\begin{aligned}
U=S_{B}\left(T_{2}-T_{1}\right)-S_{A} & \left(T_{2}-T_{1}\right)= \\
& =\left(S_{B}-S_{A}\right)\left(T_{2}-T_{1}\right) .
\end{aligned}
$$

К сожалению, в обычных металлах коэффициент Зеебека оказывается весьма малым, причем для различных металлов он может быть разных знаков (см. таблицу 1). Например, при разности температур в $300{ }^{\circ} \mathrm{C}$ в термопаре, одним из электродов которой является занимающий в

Таблица 1. Коэффициент Зеебека в обычных металлах

\begin{tabular}{|l|c|l|c|}
\hline Металл & $\begin{array}{c}\text { Коэффициент } \\
\text { Зеебека, мкВ/К } \\
\text { (относительно } \\
\text { платины) }\end{array}$ & Металл & $\begin{array}{c}\text { Коэффициент } \\
\text { Зеебека, мкВ/К } \\
\text { (относительно } \\
\text { платины) }\end{array}$ \\
\hline Висмут & $-73,0$ & Серебро & $+7,1$ \\
Никель & $-16,4$ & Медь & $+7,4$ \\
Палладий & $-5,6$ & Железо & $+16,0$ \\
Калий & $-9,0$ & Сурьма & $+47,0$ \\
\hline
\end{tabular}


таблице лидирующее положение висмут $\left(S_{B}=-73\right.$ мкВ/К), а вторым сурьма $\left(S_{A}=47\right.$ мкВ/К), создаваемое напряжение составит около 36 мВ. Таким образом, чтобы заменить две обычные пальчиковые батарейки, используемые в компьютерных мышках, пультах и многих других гаджетах, пришлось бы соединить 80 таких термопар и поддерживать между их электродами разность температур в $300{ }^{\circ} \mathrm{C}$. Это уж слишком!

\section{Дальнейшая судьба открытия Зеебека}

Термоэлектричество довольно быстро нашло свое применение, во всяком случае в физических лабораториях. Так, известный всем закон Ома был открыт и описан Георгом Симоном Омом в двух статьях, 1826 и 1827 годов. После опубликования первой статьи Ому посоветовали отказаться от гальванической батареи, поскольку за время измерения электродвижущая сила такого источника существенно изменялась. Более точные результаты измерений для второй статьи уже были получены благодаря использованию как раз термоэлектрического источника тока (пара медь висмут), способного поддерживать постоянное напряжение.

Далее исследования открытого Зеебеком явления продолжились в 1830-е годы в работах Жана Пельтье, где был обнаружен обратный термоэлектрический эффект: нагревание или охлаждение стыка двух проводников при протекании через него электрического тока. Его суть несколькими годами позже исследовал российский физик немецкого происхождения, один из основоположников электротехники Генрих Фридрих Эмиль Ленц. Он поместил каплю воды в углубление на стыке двух стержней из висмута и сурьмы (с сопротивлением $R$ ) и обнаружил, что при протекании электрического тока $(I)$ в одном направлении капля превращалась в лед, при смене же направления на противоположное лед таял. Этот простой и впечатляющий эксперимент показал, что при протекании через контакт двух различных металлов тока, помимо известного джоулева тепла $\left(I^{2} R\right)$, выделяется или погло- щается дополнительное тепло, пропорциональное первой степени тока. Последнее получило название тепла Пельтье.

Да, а что же термоэлектричество? Вплоть до середины 30-х годов XX века не существовало понимания на микроскопическом уровне устройства и металлов. Для создания соответствующей теории было необходимо как минимум вначале понять структуру составляющих их атомов, а необходимый для этого математический и понятийный аппарат - квантовая механика был сформулирован только в конце 20-х годов. Тем не менее, на феноменологическом уровне понимание явления термоэлектричества продвигалось вперед. Во второй половине XIX века в работах Гиббса, Больцмана и других ученых развивается новая область физики - статистическая механика, изучающая системы большого числа частиц. Возможность описывать их свойства с помощью классической механики иллюзорна: не только решить, но и даже выписать уравнения классической механики для большого количества частиц не представляется возможным. Взамен ученые обнаруживают для таких системы совершенно новые, так называемые статистические закономерности. Они понимают, что для необходимого описания свойств здесь лишняя информация (координаты, скорости всех частиц) просто не нужна. Следует научиться задавать Природе новые вопросы и понять, как получить на них ответы.

В числе прочих новых понятий Джозайя Уиллард Гиббс в 1875 году вводит $х и м и-$ ческий потенциал $\mu$ - энергию, которую следует затратить для добавления в систему большого числа частиц еще одной частицы. В условиях равновесия эта величина остается постоянной по всему объему системы - иначе бы частицы перетекали с одного места на другое. Понятие химического потенциала легко обобщить и на случай пребывания системы во внешнем поле, под которым мы в дальнейшем будем подразумевать электрическое поле с потенциалом $\varphi$. Для этого к химическому потенциалу $\mu$ нужно просто добавить соответствующую потенциальную энергию частицы с 
зарядом $q$, приобретаемую ею при попадании в систему. Теперь уже условием равновесия оказывается постоянство электрохимического потенциала $\mu+q \varphi$.

Вернемся к опытам Алессандро Вольта 1794 года. Противоположные концы железного проводника он помещал в кипящую и ледяную воду, создавая тем самым в системе находящихся в металле свободных электронов градиент температуры. Эти электроны вместе с нагревателем и холодильником, строго говоря, равновесную систему не представляют: для поддержания разности температур к ней следует непрерывно подводить и отводить тепло. Однако если концы не соединены между собой в электрическую цепь (скажем, лягушачьей лапкой), то электроны перемещаются в первый момент так, чтобы их плотность соответствовала локальной температуре (как у любого газа при постоянном давлении: где холоднее, там плотность больше). Однако, ведь электроны являются заряженными частицами, поэтому внутри металла возникает отличное от нуля электрическое поле, а между концами проводника - разность потенциалов. Вот вам и объяснение термоэлектричества, достаточно лишь знать о существовании в металле свободных электронов (сам электрон был открыт лишь в 1897 году).

Как вышесказанное превратить в полезную формулу для коэффициента Зеебека? Понадобятся всего несколько строчек. Электрохимический потенциал в проводнике остается постоянным:

$$
\mu+q \varphi=\text { const. }
$$

Следовательно, его производная по координате (проводник мы считаем одномерным) равна нулю:

$$
\frac{d \mu}{d x}+q \frac{d \varphi}{d x}=0 .
$$

Последняя производная есть не что иное как взятая с противоположным знаком напряженность электрического поля: $E=-d \varphi / d x$. Таким образом, мы приходим к уравнению

$$
\frac{d \mu}{d x}=q E .
$$

Химический потенциал теперь меняется от точки к точке и зависит от локального значения температуры. Поэтому его производную можно вычислить, вначале продифференцировав по температуре, а уже затем продифференцировав последнюю по координате:

$$
\frac{d \mu}{d x}=\left(\frac{d \mu}{d T}\right)\left(\frac{d T}{d x}\right) .
$$

Таким образом, мы приходим к так называемой формуле Кельвина, связывающей коэффициент Зеебека с производной химического потенциала по температуре:

$$
S=\frac{E}{\Delta T / \Delta x}=\frac{1}{q} \frac{d \mu}{d T} .
$$

Скажем сразу, что она не описывает термоэлектрический эффект во всех случаях жизни, но, тем не менее, окажется чрезвычайно полезной для нашего дальнейшего рассказа.

\section{Как живется электронам в металле?}

Прежде чем применить формулу Кельвина к вычислению коэффициента Зеебека для металла, давайте разберемся, как в металле живут электроны. Для этого мы начнем с одного из основополагающих соотношений квантовой механики.

В 1927 году немецкий физик Вернер Гейзенберг сформулировал принцип, называемый принципом неопределенности. Рассмотрим частицу массой $m$, которая движется по оси $x$ со скоростью $v_{x}$. Если нам удастся измерить ее скорость с точностью $\Delta v_{x}$, то ее положение $x$ оказывается невозможным определить с точностью $\Delta x$ более высокой чем $2 \hbar /\left(m \Delta v_{x}\right)$, где $\hbar=$ $=1,054 \cdot 10^{-34}$ Дж $\cdot \mathrm{c}-$ постоянная Планка. Это утверждение можно распространить и на движение частицы в трехмерном пространстве. Вместо того чтобы говорить о скорости частицы $\vec{v}$, обычно вводят ее импульс $\vec{p}=m \vec{v}$. В этом случае соотношение неопределенности записывают следующим образом:

$$
\Delta p_{x} \Delta x \geq 2 \hbar .
$$

И аналогично для двух других составляющих вектора импульса и соответствующих координат. 
Это неравенство удивительно. Законы Ньютона позволяют, исходя из начальных условий, очень точно определить положение и скорость объекта в любой момент времени. В физике Ньютона, так называемой классической механике, нет места для неопределенности. Но этот детерминизм, свойственный макроскопическому миру, перестает действовать в атомном масштабе.

Вторым важнейшим правилом сосуществования множества электронов вместе является так называемый принцип запрета Паули. Согласно ему, никакие два электрона не могут находиться в одном и том же квантовом состоянии. Состояние свободного электрона определяется его импульсом $\vec{p}=\left\{p_{x} p_{y} p_{z}\right\}$ и проекцией собственного магнитного момента - спина. Как мы уже знаем, проекция импульса электрона, например, на ось $x$ определена с точностью до $\Delta p_{x}$, а соответствующая координата - с точностью до $\Delta x$, причем произведение этих величин связано соотношением неопределенности. Таким образом, на одно состояние электрона с определенной проекцией спина должен приходиться «кубик» шестимерного пространства, объединяющего импульсы и координаты: $\Delta p_{x} \Delta p_{y} \Delta p_{z} \Delta x \Delta y \Delta z \geq(2 \pi \hbar)^{3}$. В него же можно поместить и второй электрон, с противоположной проекцией спина, но не больше. Возьмем кубик со сторонами $\Delta x=\Delta y=$ $=\Delta z=1 \mathrm{~cm}$. Тогда мы увидим, что в оставшейся трехмерной импульсной части нашего изначально шестимерного пространства первые два внесенных электрона займут расположенный в центре координат, вокруг точки $\vec{p}=0$, кубик объемом $(2 \pi \hbar)^{3} / \mathrm{cm}^{3}$. Следующие электроны уже будут вынуждены занимать состояния с ненулевыми импульсами. Постепенно, с увеличением числа электронов, которые мы приглашаем в кубик, объем занимаемых ими состояний будет возрастать, принимая форму сферы (величина импульса частицы определяет ее кинетическую энергию); полная же кинетическая энергия системы частиц будет стремиться к минимуму. Получающаяся в результате сфера

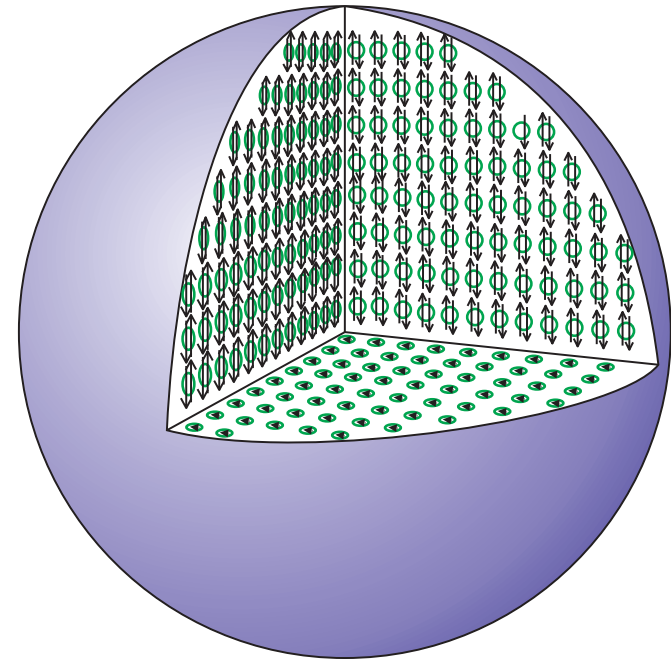

Рис.4 Сфера Ферми

называется сферой Ферми (рис.4), ее радиус $p_{\mathrm{F}}$ определяется максимальной величиной импульса, до которого мы добрались в нашем построении. Определим его.

Объем сферы составляет $\frac{4}{3} \pi p_{\mathrm{F}}^{3}$. На одно состояние приходится объем $(2 \pi \hbar)^{3}$. Тогда число таких элементарных кубиков под сферой Ферми составляет $\frac{4 \pi p_{\mathrm{F}}^{3}}{3(2 \pi \hbar)^{3}}$, да еще, чтобы определить, сколько электронов под ней вмещается, нужно найденное число умножить на 2 («спиновая» двойка отличающихся проекциями спина состояний). Таким образом, импульс Ферми определяется концентрацией электронов:

$$
n=\frac{N}{\Delta x \Delta y \Delta z}=\frac{p_{\mathrm{F}}^{3}}{3 \pi^{2} \hbar^{3}},
$$

откуда

$$
p_{\mathrm{F}}^{3}=3 \pi^{2} \hbar^{3} n
$$

Соответственно, можно найти и предельную энергию электронов, импульсы которых лежат на поверхности сферы:

$$
\varepsilon_{\mathrm{F}}=\frac{p_{\mathrm{F}}^{2}}{2 m}=\frac{3^{2 / 3} \pi^{4 / 3} \hbar^{2}}{2 m} n^{2 / 3} .
$$

В одном кубическом сантиметре металла содержится порядка $10^{23}$ атомов, которые при комнатных температурах образуют так называемый вырожденный электронный газ. Если каждый из них отдаст хотя бы по одному электрону в общее пользова- 
ние, то энергия Ферми будет порядка $5 \cdot 10^{-19}$ Дж, т.е. около 3 эВ, что соответствует температуре в 5 раз выше температуры поверхности Солнца! Скорости электронов, находящихся в импульсном пространстве у поверхности Ферми, огромны: они составляют проценты от скорости света.

\section{Химический потенциал и коэффициент Зеебека металла}

Вернемся к термоэлектричеству. Как мы уже показали, зная химический потенциал, точнее его температурную зависимость, может быть найден коэффициент Зеебека. Сам химический потенциал вырожденного электронного газа после проделанных выше вычислений находится легко: при абсолютном нуле температур он просто совпадает с энергией Ферми. Действительно, если мы хотим в обсужденный выше электронный газ, заключенный в кубик, добавить еще один электрон, то пристраивать его придется на поверхность Ферми, все остальные места внутри нее были заняты еще при построении. Таким образом,

$$
\mu(T=0)=\varepsilon_{\mathrm{F}}=\frac{3^{2 / 3} \pi^{4 / 3} \hbar^{2}}{2 m} n^{2 / 3} .
$$

Однако нам этого знания не достаточно: для нахождения коэффициента Зеебека химический потенциал следует продифференцировать по температуре, поэтому нужно узнать, как он с ростом температуры изменяется. Пусть абсолютная температура электронного газа равна $T$ и ей соответствует энергия $k T \ll \varepsilon_{\mathrm{F}}$, где $k=1,38 \cdot 10^{-23}$ Дж/К - постоянная Больцмана. Газ электронов теперь находится при отличной от нуля температуре, это означает, что электроны, прежде занимавшие состояние в пределах тонкого сферического слоя $\delta p$ такого, что $\frac{p_{\mathrm{F}}^{2}}{2 m}-\frac{\left(p_{\mathrm{F}}-\delta p\right)^{2}}{2 m} \approx \frac{p_{\mathrm{F}} \delta p}{m} \approx k T$ (шкурка дыни на рисунке 5), перемещаются во внешний слой той же ширины за пределы Фермиповерхности (обертка дыни на рисунке). Легко убедиться, что объем первого слоя составляет $3 p_{\mathrm{F}}^{2} \delta p-3 p_{\mathrm{F}}(\delta p)^{2}$, второго $3 p_{\mathrm{F}}^{2} \delta p+3 p_{\mathrm{F}}(\delta p)^{2}$, а их разность равна
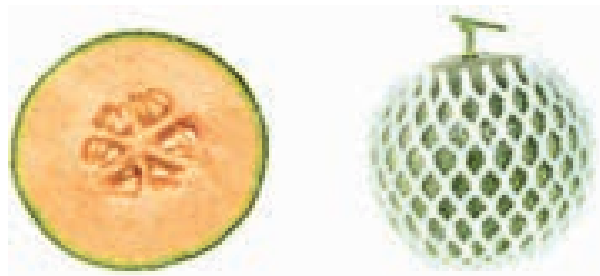

Рис. 5. Дыня - аналог области в пространстве квазиимпульсов, соответствующей заполненныМ электронныМ Состояниям

$\delta V=6 p_{\mathrm{F}}(\delta p)^{2}$. Число частиц при этом измениться не должно:

$$
\delta N=\delta(n V)=\delta n V+n \delta V=0 .
$$

Отсюда

$$
\begin{aligned}
& \frac{\delta n}{n}=-\frac{\delta V}{V}=-\frac{18 p_{\mathrm{F}}(\delta p)^{2}}{4 \pi p_{\mathrm{F}}^{3}}= \\
& =-\frac{9 m^{2}(k T)^{2}}{2 \pi p_{\mathrm{F}}^{4}}=-\frac{9(k T)^{2}}{8 \pi \varepsilon_{\mathrm{F}}^{2}} .
\end{aligned}
$$

Напомним, что существует связь между химическим потенциалом и плотностью электронов и, соответственно, малое уменьшение плотности приведет к малому же изменению химического потенциала:

$$
\mu(T)=\varepsilon_{\mathrm{F}}\left(1-\frac{9(k T)^{2}}{8 \pi \varepsilon_{\mathrm{F}}^{2}}\right)^{2 / 3} \approx \varepsilon_{\mathrm{F}}-\alpha \frac{(k T)^{2}}{\varepsilon_{\mathrm{F}}}
$$

Наш очень упрощенный расчет не позволил найти правильный коэффициент $\alpha=\pi^{2} / 6$. И тем не менее, с помощью последнего выражения мы получаем, что для вырожденного электронного газа

$$
S=-\frac{\pi^{2} k^{2}}{3 e} \frac{T}{\varepsilon_{\mathrm{F}}} .
$$

Отсюда сразу же становится понятно, почему эффект Зеебека столь слаб в хороших металлах, где величина энергия Ферми очень велика $\left(\varepsilon_{\mathrm{F}} \approx 3\right.$ эВ). Так, для комнатных температур наша оценка приводит к величине для коэффициента Зеебека порядка нескольких микровольт на кельвин, что делает их малопригодными для использования в качестве термоэлектрических генераторов напряжения.

\section{Эффект Зеебека в полупроводниках}

Существуют оценки показывающие, что стоимость электроэнергии, вырабатывае- 
мой в начале XX века непосредственным сжиганием топлива в паровом котле и преобразованием давления пара в механическую работу, была почти в 40 раз ниже стоимости электроэнергии, вырабатываемой доступными в то время термоэлектрическими источниками. И только в 1929 году, основываясь на экспериментальном обнаружении высоких значений (в сотни микровольт на кельвин) коэффициента Зеебека в полупроводниках, Абрам Федорович Иоффе выдвинул идею, что для повышения КПД термоэлементов следует заменить металлы полупроводниками. Понять, почему именно полупроводники являются более перспективными материалами для термоэлектрических источников энергии, можно следующим образом.

При оценке коэффициента Зеебека в металлах мы использовали тот факт, что число электронов не меняется. В полупроводниках это не так - концентрация носителей заряда очень сильно (экспоненциально) зависит от температуры, приводя к гораздо более сильной зависимости химического потенциала от нее. Это и обуславливает большие значения коэффициента Зеебека в полупроводниках.

Они особенно велики в так называемых легированных полупроводниках, которые похожи на рассмотренные выше металлы. В них для изменения электрических свойств специально добавляются примеси, которые, встраиваясь в кристаллическую решетку, сбрасывают с себя (или отнимают) лишние электроны. В результате в таком полупроводнике, подобно тому как мы уже видели на примере металла, образуется газ свободных электронов. Поскольку концентрация примесей по сравнению с концентрацией атомов самого полупроводника всегда мала, то малой оказывается и соответствующая энергия Ферми. При достаточно низких температурах (a ими вполне могут быть и комнатные температуры) этот газ оказывается вырожденным, и для соответствующего коэффициента Зеебека полупроводника можно воспользоваться полученной нами формулой (*), только энергия Ферми в ней будет составлять не электронвольты, а всего
Таблица 2. Коэффициент Зеебека в полупроводниках

\begin{tabular}{|l|l|c|}
\hline Вещество & $\begin{array}{l}\text { Электрические } \\
\text { свойства }\end{array}$ & $\begin{array}{c}\text { Коэффициент } \\
\text { Зеебека, мкВ/К }\end{array}$ \\
\hline Висмут & Металл & -73 \\
Константан & Металл & -35 \\
Никель & Металл & -15 \\
Платина & Металл & 0 \\
Алюминий & Металл & 3,5 \\
Германий & Полупроводник & 300 \\
Кремний & Полупроводник & 440 \\
Теллур & Полупроводник & 500 \\
Селен & Полупроводник & 900 \\
\hline
\end{tabular}

лишь десятки или сотни миллиэлектронвольт. Соответственно, и коэффициент Зеебека возрастет в десятки или сотни раз по сравнению с его значениями в металлах (см. таблицу 2).

\section{Коэффициент полезного действия термоэлектрического генератора и методы его повышения}

Коэффициент полезного действия $\eta$ термоэлектрического устройства определяется отношением джоулевой энергии, передаваемой нагрузке за время $\Delta t$, к полной тепловой энергии, поглощенной контактом за это же время. Первая энергия, очевидно, составляет $U^{2} \Delta t / R$, где $U-$ термоэлектрическое напряжение, а сопротивление провода с удельным сопротивлением $\rho$, длиной $\Delta l$ и сечением $A$ равно $R=\rho \Delta l / A$. Вторая энергия равна произведению теплового потока $q=\kappa \Delta T / \Delta l$, где к - теплопроводность, площади сечения $A$ контакта и времени $\Delta t$. Таким образом,

$$
\begin{aligned}
& \eta=\frac{U^{2} \Delta t / R}{q A \Delta t}=\frac{S^{2}(\Delta T)^{2} \Delta t}{\frac{\rho \Delta l}{A} \cdot \kappa} \frac{\Delta T}{\Delta l} A \Delta t \\
&=\frac{\sigma S^{2}}{\kappa} \Delta T=Z T\left(\frac{\Delta T}{T}\right),
\end{aligned}
$$

где $\sigma=1 / \rho$ - электропроводность контакта. Безразмерный показатель качества $Z T=\sigma S^{2} /$ к характеризует эффективность термоэлектрического устройства, а само число $Z$ называется термоэлектрической добротностью материала, или числом 


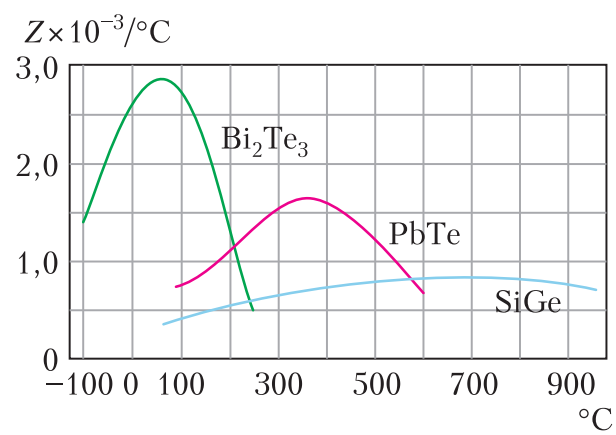

Рис. 6. Термоэлектрическая добротность трех различных термоэлектрических материалов в зависимости от температуры

Иоффе. К сожалению, для металлов показатель качества оказывается весьма мал: при характерных рабочих температурах термоэлектрических устройств он порядка $10^{-3}-10^{-4}$ (рис.6).

Понятно, что для повышения эффективности термоэлектрического устройства следует уменьшать теплопроводность используемого материала при одновременном увеличении его проводимости и коэффициента Зеебека. Как мы уже видели, последний в металлах весьма мал из-за огромной концентрации электронов и, соответственно, большой энергии Ферми. Зато электроны же обеспечивают металлу и высокую проводимость. Правда, как знает каждый, кто хоть раз размешивал сахар в чае серебряной ложечкой и обжегся, металл обладает также высокой теплопроводностью. Проводимость металла жестко связана с электронным вкладом в теплопроводность $\kappa_{e}$ законом Видемана-Франца:

$$
\frac{\sigma}{\kappa_{e}}=\frac{3 e^{2}}{\pi^{2} T} .
$$

Однако помимо электронов тепло в металле передается также и решеткой. Ее вклад $\kappa_{p}$ при комнатных температурах может оказаться весьма значительным, поэтому эффективность включит в себя сумму обеих теплопроводностей:

$$
Z T=\frac{3 e^{2}}{\pi^{2}} S^{2} \frac{\kappa_{e}}{\kappa_{e}+\kappa_{p}} .
$$

Таким образом, повышение эффективности термоэлектрического устройства на практике сводится к:
• увеличению коэффициента Зеебека материала;

• увеличению его проводимости;

• подавлению его решеточной теплопроводности.

Для того чтобы термоэлектрические устройства стали конкурентоспособными по сравнению с другими технологиями возобновляемых источников энергии (например, солнечной и геотермальной), необходимо достичь значений их эффективности $Z T \gtrsim 4$. Для достижения этой цели потребовалось огромное количество исследовательских усилий. Ниже мы познакомим вас с несколькими примерами таких работ.

\section{Новые материалы для термоэлектричества}

Термоэлектрические материалы с наноскопической структурой дефектов. Снижение теплопроводности во многом связано с продуманными изменениями структуры материала. Решетка передает тепло посредством распространяющихся по ней упругих волн. Эти волны нужно рассеивать, подобно тому как волноломы отражают штормовые волны у берегов морей и океанов. Проблема с теплопроводностью заключается в том, что рассеивать нужно колебания решетки во всех масштабах - от атомных до микронных. Этого можно добиться, наноструктурируя объемные термоэлектрики нового поколения, вводя в них разномасштабные рассеиватели колебаний решетки. Такое наноскопическое использование микроструктурных дефектов усиливает рассеяние упругих волн, не подавляя при этом электронную проводимость, что позволяет создавать термоэлектрические материалы с высокими характеристиками. В наноструктурированных термоэлектрических материалах переносящие тепло волны с малыми длинами могут рассеиваться встроенными в решетку внедрениями с характерными размерами в нанометры, в то время как волны больших длин рассеиваются на дефектах микронного диапазона с точно выверенной архитектурой. Стратегии улучшения термоэлектрических материалов направлены как на современные объемные материалы, 
Таблица 3. Термоэлектрическая добротность наиболее перспективных термоэлектрических материалов

\begin{tabular}{|l|c|l|}
\hline \multicolumn{1}{|c|}{ Материалы } & $Z T$ & \multicolumn{1}{c|}{ Комментарии } \\
\hline $\begin{array}{l}\text { Оксиды со слоистой } \\
\text { структурой }\left(\mathrm{SrTiO}_{3}\right)_{n}(\mathrm{SrO})_{m}\end{array}$ & $\begin{array}{c}\sim 0,34 \\
\text { при } 1000 \mathrm{~K}\end{array}$ & $\begin{array}{l}\text { Весьма перспективные } \\
\text { для применения при } \\
\text { высоких температурах }\end{array}$ \\
\hline $\begin{array}{l}\text { Халькогениды висмута } \\
\left(\mathrm{Bi}_{2} \mathrm{Te}_{3}, \mathrm{Bi}_{2} \mathrm{Se}_{3}\right)\end{array}$ & $\begin{array}{c}\sim 0,8-1,0 \\
\text { комн. темп. }\end{array}$ & $\begin{array}{l}\text { Не зависящее от } \\
\text { температуры } Z T\end{array}$ \\
\hline $\begin{array}{l}\text { Наноструктурированные } \\
\text { халькогениды висмута } \\
\left(\text { трехслойные } \mathrm{Bi}_{2} \mathrm{Te}_{3}, \mathrm{Bi}_{2} \mathrm{Se}_{3}\right)\end{array}$ & $\begin{array}{c}\text { при } 2,4 \\
\text { комн. темп. }\end{array}$ & $\begin{array}{l}\text { Обладают высокой } \\
\text { электропроводностью }\end{array}$ \\
\hline $\begin{array}{l}\text { Кремний-германиевые } \\
\text { сплавы }\end{array}$ & $\begin{aligned} \sim 0,7 \\
\text { комн. темп. }\end{aligned}$ & $\begin{array}{l}\text { Наилучшие термоэлек- } \\
\text { трические материалы } \\
\text { при температурах - } \\
1000 \mathrm{~K}\end{array}$ \\
\hline
\end{tabular}

тались неэффективными для использования рассеиваемого тепла.

Совсем недавно новый импульс поискам пригодных для практических применений термоэлектрических материалов придали исследования ионных жидкостей. Последние представляют собой расплавленные соли, жидкие как при комнатной температу- так и на использование низкоразмерных систем.

Наноструктурирование термоэлектрических материалов на основе полупроводников, снижающее теплопроводность решетки при увеличении коэффициента Зеебека, привело к заметным улучшениям в преобразовании тепловой энергии в электрическую. Однако даже самые перспективные материалы пока не смогли преодолеть минимальное требование $Z T=4$ (см. таблицу 3). Кроме того, созданные на сегодняшний день наноструктурированные материалы имеют ряд технологических, экологических и экономических недостатков, таких как ограниченные размеры, немалые затраты на производство и содержание редких и токсичных материалов.

Термоэлектричество в электролитах и ферромагнитных жидкостях. Ученые продолжают искать экологически чистые и экономичные новые типы термоэлектрических материалов, таких как полимеры, ионные проводники и др. Одним из таких объектов недавно стали жидкие электролиты. Оказывается, что значения коэффициента Зеебека у них обычно на порядок больше ( $S \approx 0,5$ мВ/К), чем у полупроводниковых, даже наноструктурированных материалов. Кроме того, они состоят из доступных и нетоксичных элементов. К сожалению, электрическая проводимость таких жидкостей на несколько порядков меньше, чем у легированных полупроводников, поэтому жидкие электролиты счи- ре, так и при температурах намного выше $100{ }^{\circ} \mathrm{C}$ (некоторые могут превышать и $300{ }^{\circ} \mathrm{C}$ ). В отличие от жидких электролитов, наряду с большими коэффициентами Зеебека ионные жидкости обладают высокой электропроводностью, что обеспечивает их высокую эффективность $(Z T \approx 2)$. Таким образом, ионные жидкости являются перспективными кандидатами для утилизации тепловых потерь (рис.7). Например, для преобразования тепла выхлопной трубы автомобиля в электроэнергию, которой будет достаточно для работы кондиционера, охлаждающего его салон.

Коэффициент Зеебека жидких электролитов может быть также увеличен посредством введения в их объем магнитных наночастиц (феррожидкость). Их медленный дрейф под воздействием разности температур и взаимодействие с электрода-

$$
S, \mathrm{M \kappa \textrm {B }} / \mathrm{K}
$$

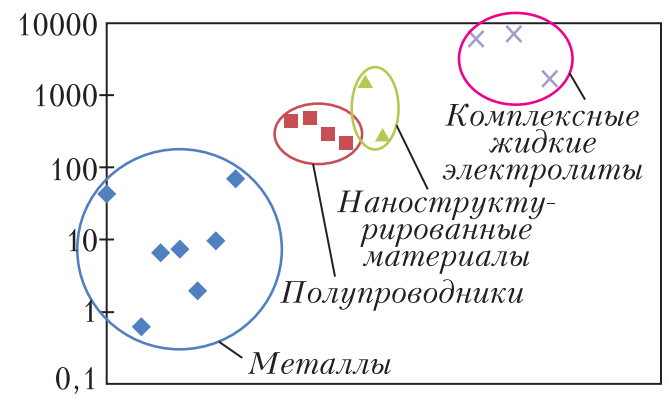

Рис. 7. Значения коэффициента Зеебека для различных классов термоэлектрических материалов 
ми улучшают термоэлектрические свойства жидкости. Имеющееся понимание термоэлектрохимической природы сложных жидкостей еще далеко от полноты. Однако в этой захватывающей области ведутся активные экспериментальные и теоретические исследования, обещающие долгожданные применения в утилизации тепловых потерь, наносящих вред не только экономический, но и экологии окружающей нас среды. Упомянутые выше феррожидкости являются рабочим телом для термоэлектрических генераторов нового поколения, разрабатываемых в настоящее время учеными консорциума MAGENTA нескольких европейских лабораторий.

\section{Несколько слов о применениях}

Термоэлектрические устройства имеют широчайшую область применений, начиная от выработки электроэнергии и заканчивая термоэлектрическими приемниками излучения. Надежность и простота термоэлектрических устройств позволяет использовать их даже тогда, когда традиционные источники энергии более эффективны. Помимо термопар достаточно широко используются устройства, работающие на принципе эффекта Пельтье: охладители для различных продуктов, начиная от оптоэлектроники, небольшие холодильники, системы охлаждения/обогрева сидений в автомобилях. В качестве рабочего материала в таких устройствах, как правило, используется полупроводниковая пара $\mathrm{Bi}_{2} \mathrm{Te}_{3}-\mathrm{Sb}_{2} \mathrm{Te}_{3}$.

Жюль Верн в своем романе «Двадцать тысяч лье под водой», который вышел в 1870 году, обсуждал возможность того, что источником энергии для «Наутилуса» могла бы быть термоэлектрическая батарея, работающая за счет разности температур воды на разных глубинах. Современные атомные подводные лодки, как мы знаем, используют более традиционные паровые турбины. Но вот на космических аппаратах, которые направляются в глубины космоса, действительно стоят термоэлектрические источники энергии. Дело в том, что за пределами планеты Марс солнечный свет слишком слаб для питания космического корабля солнечными батареями. Поэтому необходимая для функционирования бортовых систем электроэнергия обеспечивается путем преобразования тепла, выделяющегося при радиоактивном распаде $\mathrm{Pu}^{238}$, в электричество с использованием термоэлектрических пар. Такие радиоизотопные термоэлектрические генераторы использовались НАСА в различных миссиях, таких как «Аполлон», «Пионер», «Викинг», «Вояджер», «Галилео» и «Кассини». Источники питания для «Вояджера» без движущихся частей все еще работают, что позволяет космическому кораблю продолжать научные исследования после более чем 35 лет эксплуатации. Радиоизотопный термоэлектрический источник электроэнергии массой 45 кг, дающий мощность в 110 Вт, стоит и на недавно начавшем изучать Марс марсоходе «Perseverance».

Авторы благодарят за поддержку программу исследований и инноваций Европейского союза Horizon 2020, грантовое соглашение №731976 (MAGENTA), а также выражают признательность Ломбардской академии наук и литературы (Милан) за любезное предоставление факсимиле из архива трудов Алессандро Вольты.

\section{Вниманию наших читателей}

Подписаться на журнал “Квант» можно с любого номера в любом почтовом отделении. Наш подписной индекс в каталоге "Пресса России» - 90964.

Купить журнал "Квант» возможно в магазине "Математическая книга» издательства МЦНМО (адрес интернет-магазина: biblio.mccme.ru), а также в московских книжных магазинах "Библио-глобус», "Молодая гвардия», "Московский дом книги» и в редакции журнала.

Архив вышедших номеров журнала “Квант» имеется на сайте http:/ / kvant.ras.ru 